\title{
“O MENINO QUE DESCOBRIU O VENTO": REFLEXÕES SOBRE LEITURA E TRANSFORMAÇÃO SOCIAL
}

DOI: $10.48075 / R I . V 24 I 2.26633$

\begin{abstract}
Marieli Rosa ${ }^{1}$
Cindy Mery Gavioli-Prestes ${ }^{2}$

Micheli Rosa ${ }^{3}$

RESUMO: Levando em consideração o pensamento freireano acerca da leitura do mundo e a noção de letramento nos termos de Soares (2014) e nas discussões de Rojo (2009) e Kleiman (2004), temos como objetivo neste trabalho discutir de que forma essa prática pode ser observada em William Kamkwamba, protagonista do longa-metragem "O menino que descobriu o vento", de 2019. Ao ver sua aldeia, em Malauí, na África, devastada pela seca, pela fome e pela miséria, William é capaz de ler seu mundo (Freire, 2000) e, por meio da leitura de um livro, Using the energy, ele consegue ajudar sua aldeia. Dessa forma, refletimos as leituras de mundo enquanto contribuição crítica para a formação do cidadão. Para isso, evocamos as contribuições de Mikhail Bahktin (2003; 2009) para compreender as relações entre o "eu" e "outro", pois o sujeito constitui e é constituído pelas relações sociais e culturais. As conexões entre as fases, apresentadas durante o filme, representam as ligações entre conhecimento, natureza e sociedade, ou seja, imagens de um leitor menino, que não leu somente um livro, mas, seu mundo, seu presente e seu passado.
\end{abstract}

Palavras-chave: ensino; leitura; letramento.

\section{"THE BOY WHO HARNESSED THE WIND": REFLECTIONS ON READING AND SOCIAL TRANSFORMATION}

ABSTRACT: Considering the thought Freirean about world reading and the notion of literacy in the terms of Soares (2014), and in the reflections carried out in Rojo (2009), and Kleiman (2004), we aim at this paper to discuss how this practice can be observed in William Kamkwamba, protagonist of the feature film "The boy who discovered the wind", 2019. Seeing his village in Malawi, Africa, devastated by drought, by hunger and misery, William can read his world (Freire, 2000) and, through

\footnotetext{
${ }^{1}$ Mestranda em História pela Universidade Estadual de Ponta Grossa. Pesquisadora nos grupos de pesquisa em Linguística Forense e Ensino de língua e literatura. E-mail: marielly rosa@yahoo.com.br

2 Doutora em Letras pela Universidade Federal do Paraná e professora na Universidade Estadual do CentroOeste. Líder do grupo de pesquisa Gramática(s) em perspectiva e pesquisadora nos grupos de pesquisa em Linguística Forense e Ensino de língua e literatura. E-mail: cprestes@unicentro.br

${ }^{3}$ Mestranda em História pela Universidade Estadual de Ponta Grossa. Pesquisadora nos grupos de pesquisa em Linguística Forense e Gramática (s) em perspectiva (s). E-mail: michelly.hist@gmail.com
} 
the reading of a book, Using the energy, he can help his village. Thus, we reflect the readings of the world as a critical contribution to the formation of the citizen. To this end, we evoke the contributions of Mikhail Bahktin (2002) to understand the relations between the "I" and "other" because, the subject constitutes and is constituted by social and cultural relations. The connections between the phases, presented during the film, represent the links between knowledge, nature, and society, that is, images of a boy reader, who has not only read a book, but, his world, his present and his past.

Key Words: teaching, reading, literacy.

\section{INTRODUÇÃO}

A sociedade brasileira, nos últimos anos, tem vivenciado discursos de ódio e de intolerância. Os governantes atacam cada vez mais os direitos civis e sociais em prol da fortificação dos interesses neoliberais, assim, em governos cuja finalidade é a defesa dos interesses das classes dominantes, a Educação torna-se alvo no campo ideológico e político. Ao refletirmos a importância histórica do acesso das classes subalternas aos espaços escolares compreendemos por que as Ciências e a escola são alvos de desmantelamento.

Ao pensarmos a educação, vemos que não é possível separá-la do contexto em que os sujeitos estão inseridos. Dessa forma, a leitura do mundo somada com as trocas de experiências entre sujeitos proporciona a construção de práticas libertadoras. No centro dos estudos de Freire, está localizada a educação como prática de liberdade, na qual a realidade é propulsora para a conscientização. A educação deve ser, então, um instrumento capaz de problematizar as questões sociais, a partir do diálogo e do respeito, instrumentalizando os sujeitos para o exercício da cidadania.

No presente artigo, apresentamos discussões sobre a importância da leitura para a formação dos sujeitos históricos enquanto cidadãos, mostrando que a leitura do mundo e a leitura da palavra dialogam e constroem mutuamente a criticidade. Para isso, levaremos em conta um longa-metragem em que observamos as ações da personagem principal, Willian Kamkwamba, no filme O menino que descobriu o vento (2019), produção exclusiva da Netflix. Esse filme é baseado na história real de um garoto que encontrou uma maneira de ajudar sua família e seu vilarejo em Malauí, que, em 2001, foi devastado por um período longo de seca, fome e miséria.

Este estudo realça a importância entre as leituras e o contexto social em que o sujeito está inserido no qual o diálogo é propulsor para a transformação social. Para atingir 
esse objetivo proposto, as análises da trajetória do protagonista do filme são amparadas pelas discussões propostas por Paulo Freire (1989), sobre a leitura do mundo e da palavra, assim como, a relação entre sujeito e contexto. Empreendemos discussões sobre a ressignificação a partir do outro, através do diálogo, e a educação como transformadora da realidade de forma consciente e libertadora. Além disso, as contribuições de Bakhtin (2003; 2009) sobre o "eu" e o "outro" são pertinentes para compreender as relações entre sujeito e sociedade.

Com isso, pretendemos, através das análises das cenas selecionadas, compreender as inúmeras leituras que William fez de seu mundo e para isso conectamos aspectos das esferas, denominada pelas autoras, Ciência/conhecimento, Natureza e Sociedade, pois, a personagem principal dialoga com tais esferas, as lê e, assim, as interpreta. Um sujeito capaz de aprender, de ensinar e de transformar a realidade de sua aldeia.

Com o intuito de alcançarmos os objetivos, apresentamos na primeira seção nosso embasamento teórico, discutindo a questão da leitura para Freire e a relação entre letramento(s) e sociedade. Em seguida, levando em consideração o que foi exposto, passamos para a análise das ações do protagonista do filme. Por fim, a partir de todas as discussões realizadas, trazemos nossas considerações finais.

\section{A LEITURA PARA ALÉM DOS LIVROS: REFLEXÕES SOBRE LETRAMENTO, SOCIEDADE E TRANSFORMAÇÃO SOCIAL}

Em Linguística Aplicada, a partir dos estudos sobre letramento(s), como os realizados por Kleiman (2004), Rojo (2009), dentre outros, a leitura é compreendida como uma prática social, ou seja, está relacionada ao meio social e cultural do sujeito. Estuda-se a multiplicidade das diferenças situacionais entre leitor e leitura e seus diferentes modos de ler. De acordo com Kleiman (2004, p. 15), os modos de ler são inseparáveis dos contextos de ação dos leitores, pois os "modos de ler interessam pelo que nos podem mostrar sobre a construção social dos saberes em eventos que envolvem interações, textos multissemióticos e mobilização de gêneros complexos".

A leitura não se refere somente ao conhecimento ou decodificação do alfabeto ou os sons da fala. Para compreender o que se lê é necessário acionar o conhecimento de mundo, bem como relacioná-lo com o texto/discurso e, inclusive, com outros textos (intertexto). 0 letramento envolve os usos de práticas sociais de linguagem que recobrem contextos sociais 
diversos. Seu caráter é revolucionário e crítico "na medida em que colaboraria não para adaptação do cidadão às exigências sociais, mas para o resgate da autoestima, para construção de identidades fortes para a potencialização de poderes" (ROJO, 2009, p. 100).

O educador e patrono da educação brasileira aponta que o ato de ler envolve o âmbito social e cultural. Assim, as leituras não se restringem a textos escritos, mas a nossa vida, pois

[...] a leitura do mundo precede a leitura da palavra, daí que a posterior leitura desta não possa prescindir da continuidade da leitura daquele. Linguagem e realidade se prendem dinamicamente. A compreensão do texto a ser alcançada por sua leitura crítica implica a percepção das relações entre o texto e o contexto. (FREIRE, 1989, p. 9).

Rojo (2004, p. 1-2) ressalta, ainda, que a leitura do texto deve ser direcionada para realidade social do leitor. Para a autora, o leitor crítico e reflexivo é capaz de "escapar da literalidade dos textos e interpretá-los, colocando-os em relação com outros textos e discursos, de maneira situada na realidade social", ou seja, colocar os textos em relação e contraposição à vida. Por criticidade e reflexividade, compreende-se as atribuições de sentidos, de conexões e de significações atribuídas pelo leitor a partir de sua leitura e decodificação.

$O$ ato de ler e sua relação com o mundo material transforma o simples saber mecânico em "um saber socialmente útil, um saber para mundo social e histórico, que supra necessidades da vida humana social" (CRUZ; BIGLIARDI; MINASI, 2014, p. 43). Em síntese, o leitor crítico e reflexivo é capaz de transformar o saber para a vida.

Envolver os aspectos sociais, as experiências concretas e reais dos sujeitos no ato de ler é um compromisso da Educação, visto que ao "envolver a própria vida em processo no aprender e no ensinar a partir da construção do real" (LIMA, 2014, p. 69), possibilita-se a criticidade sobre as estruturas sociais no qual os alunos estão inseridos. Dessa forma, segundo Martins (1988, p. 17), "o leitor pré-existe à descoberta do significado das palavras", ou seja, suas experiências de vida oriundas do seu universo cultural e social tornam-se fundamentais para a compreensão e leituras dos textos.

Por conseguinte, concebemos a leitura do mundo como primordial para a compreensão do dialogismo entre realidade e leituras. Considerando as reflexões acima, pontuamos que o ato de ler - seja um gesto, uma imagem, um som, uma frase etc. - é, em sua constituição, o diálogo entre o leitor e o tempo/espaço em que está localizado. Dessa 
forma, as vivências interferem no processo das múltiplas leituras. Assim aprender a ler significa também ler o mundo. Lemos, para o bem ou para o mal, o mundo em que vivemos.

A leitura nunca é um ato solitário, pois o leitor do mundo/da escrita faz parte de um grupo social e carrega consigo elementos de cultura e de modos de vivências. Texto e contexto, para Freire, têm conexão intrínseca. O sujeito "não apenas está no mundo, mas com o mundo. Estar com o mundo resulta de sua abertura à realidade, que o faz ser o ente de relações que é" (FREIRE, 1967, p. 39).

Ao denominar os sujeitos como seres transformadores da realidade $\mathrm{e}$ transformados por ela, o educador refere-se ao movimento constante de mudança a que passamos durante a vida. Ao pensarmos a constituição do sujeito pela linguagem, em uma concepção bakhtiniana, adentramos na ideia de sujeito inconcluso, pois o "eu" constitui-se pela visão do "outro" e pelas interações sociais.

A mediação entre ser humano e o mundo é um dos centros de discussão na obra freiriana e, assim, somos capazes de, através da ação, transformar a sociedade. "Existir, humanamente, é pronunciar o mundo, é modificá-lo. O mundo pronunciado, por sua vez, se volta problematizado aos sujeitos pronunciantes, a exigir deles novo pronunciar" (FREIRE, 1987, p. 44).

Nas palavras de Freire $(1987$, p. 45), encontramos a representação da transformação social via Educação, ou seja, para o autor, há grande poder de transformação através da leitura e da educação e por conta disso é de suma importância reivindicarmos o direito da palavra de todos.

É preciso primeiro que, os que assim se encontram negados do direito primordial de dizer a palavra, reconquistem este direito, proibindo que este assalto desumanizante continue. Se é dizendo a palavra com que, 'pronunciando' o mundo, os homens o transformam, o diálogo se impõe como caminho pelo qual os homens ganham significação enquanto homens. Por isto, o diálogo é uma exigência existencial. (FREIRE, 1987, p. 45).

Levando em consideração esse diálogo e a questão do papel da escola, vemos que a formação da consciência coletiva na escola é parte importante para a transformação social dos indivíduos. No entanto, vale ressaltar que as leituras ultrapassam os muros das instituições e, assim, o processo de reconhecer-se no mundo é um diálogo constante com outros sujeitos, enquanto atores sociais e participantes da história. A contribuição de Freire 
é para uma "educação como prática da liberdade tomando a conscientização como mola propulsora da realidade social" (LIMA, 2014, p. 70).

Portanto, ele preocupou-se em tornar as palavras relevantes na vida das pessoas a partir do processo de conscientização da realidade social. Suas discussões apresentam reflexões importantes no campo do ensino, dos letramentos e da educação, pois apontam para práticas de liberdade e emancipação das pessoas. A partir das condições sociais e econômicas representadas no filme $O$ menino que descobriu o vento (2019) analisaremos a trajetória de um jovem que reconquistou o "direito de dizer a palavra" e "transformou seu mundo através dela".

\section{O MUNDO PELOS OLHOS DE WILLIAM KAMKWAMBA}

Tendo como suporte tudo o que foi exposto na seção anterior, passaremos para a análise da personagem William Kawkwamba no filme $O$ menino que descobriu o vento (Boy Who Harnessed the Wind), que é baseado em uma história real e foi lançado pela Netflix em 2019, tendo sido dirigido por Chiwetel Ejiofor. A produção baseou-se no livro The Boy Who Harnessed the Wind, escrito por William Kawkwamba e Bryan Mealer, lançado em 2013.

Para expormos nossa análise, vamos dividi-la em duas frentes: inicialmente, apresentaremos a trajetória da personagem, buscando relatar a trama e focalizar cenas, selecionadas por nós, em que se percebem as observações feitas por William e, em seguida, discutiremos as leituras dialéticas da personagem.

a) Entre as fases: a trajetória de O menino que descobriu o vento (2019)

Ao olharmos o mundo por uma janela, certamente, iremos vislumbrar uma fração dele, mas esse pequeno espaço sempre é um convite para o conhecimento pleno do mundo (LIMA, 2012). Dessa forma, a personagem William Kamkwamba nos convida a olharmos por outras janelas e, assim, a problematizar e a refletir sobre a leitura e a transformação social.

O filme conta a história de um garoto de 13 anos que vive em Malauí, país da África Oriental, devastada por inundações e, posteriormente, pela seca em 2001. Os problemas advindos do clima, da escassez de mantimentos e a falta de posicionamento governamental frente aos problemas sociais e econômicos trouxeram a miséria, a fome e a morte para muitas aldeias. É nesse cenário que se encontra William Kawkwamba, um jovem capaz de observar, agir e, principalmente, ler seu mundo. 
No início, deparamo-nos com as questões acerca do desmatamento das árvores por parte de agentes do governo e com as mudanças climáticas que afetam a agricultura, as comunidades locais e suas respectivas produções. Como as áreas onde havia árvores que impediam inundações em tempos de chuvas intensas foram vendidas e desmatadas, um longo período de seca inviabilizou o plantio e a colheita de grãos por dezenas de família.

Miséria, fome, violência e o descaso dos governantes compõem a narrativa da personagem principal. Em meio a essa crise, William tem seus estudos interrompidos por falta de dinheiro, mas isso não o impediu de frequentar as aulas de ciências e a biblioteca da escola de forma clandestina. Os caminhos e leituras executados pelo jovem são apresentados através de fases que se conectam a partir de aspectos sociais, econômicos e climáticos. Portanto, a narrativa orienta-nos a pensar as relações dialéticas entre sujeito, sociedade e natureza.

Para apresentarmos a trajetória do protagonista, utilizamos a divisão construída pelo filme. O longa metragem é dividido em cinco fases: kufesa (Semear), kukula (Crescer), kukolola (Colher), Njala (Fome) e Mphepo (Vento). A relação entre espaços geográficos, sociais e econômicos são primordiais para a compreensão da narrativa, pois tais elementos estão conectados e fornecem relações dialógicas para compreender a trajetória e a leitura do mundo da personagem principal. O tempo da natureza interliga-se com o tempo social e econômico, haja vista que a agricultura marca a relação entre sujeito, natureza e cultura.

A fase Kufesa (Sowing/Semear) inicia com imagens de um campo de plantio no qual o avô de William falece em meio as plantações. No funeral, temos os familiares e amigos próximos numa cerimônia com características cristãs. Durante essa cena, ouvem-se sons de tambores e lamentos; as pessoas levantam-se e seguem a melodia. Surge, no horizonte, outro grupo cuja representação tem caráter ancestral, local e singular. Eles praticam o Gule Wamkulu, uma dança em que os membros demonstram afeto e solidariedade durante 0 funeral.

Na cena subsequente, observamos William consertando um rádio em troca de algum valor em dinheiro. Depois, temos a cena em que seus pais preparavam uma surpresa: colocaram na cama de William o uniforme da escola. Ao entrar no quarto, ele descobre que integrará o quadro de discentes da escola Kachokolo. Salienta-se que o acesso à escola é possível somente mediante pagamento das mensalidades, pois, em Malauí, a educação não 
é pública. Após vestir-se, o garoto dirige-se para escola acompanhado de sua companheira inseparável: Khamba, uma cachorrinha.

No final da aula, o professor de ciências, Mike Kachigunda, adverte William sobre o pagamento das mensalidades para continuar frequentando a escola. Em casa, percebemos as dificuldades enfrentadas pelo jovem. Pois, por falta de iluminação a personagem principal não consegue estudar no período noturno. Por conseguinte, ele adquiriu a nota de 6.2 na prova de ciências e, como iniciativa para mudar isso, convidou seu amigo Gilbert para ir ao aterro sanitário da indústria do tabaco com a finalidade de encontrar algo que pudesse servir para os estudos. Por fim, encontram uma bomba d'água e uma bateria descarregada.

De volta para a vila, os jovens entram na casa do Chefe Wiembe. Estava acontecendo uma reunião sobre a venda de terrenos para representantes do governo. O Chefe conversou com os integrantes da comunidade a respeito do fato de que as árvores impedem inundações e protegem as plantações e, ressaltou, que os governantes sabiam da probabilidade de estiagem e um longo período de seca. Porém, alguns membros não o escutaram e venderam suas partes. A autorização viabilizava o governo a desmatar as áreas vendidas.

Em seguida, temos a cena, que intitulamos Desmatamento das árvores, figura 1, em que William constrói uma armadilha para pássaros e é surpreendido pelo som da motosserra. Nesse momento, ele se levanta e verifica que há um grupo de homens com máquinas derrubando as árvores que pertenciam aos terrenos vendidos pelos membros da comunidade.

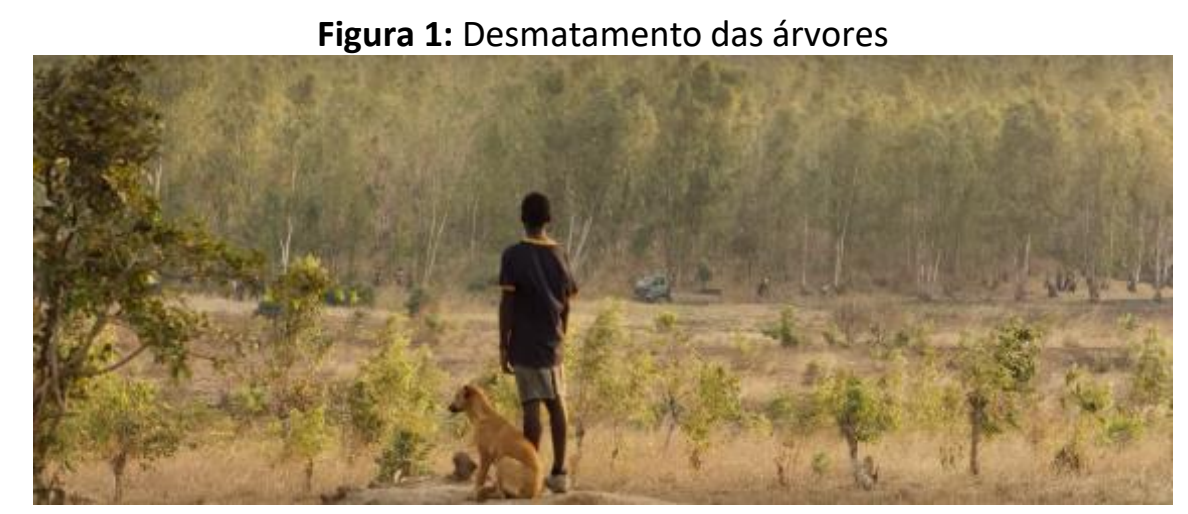

Fonte: O menino que descobriu o vento (2019)

Em seguida, William consegue caçar um pássaro e leva-o para um estabelecimento, frequentado por garotos mais velhos, em que sua entrada é permitida porque fornece sua 
caça como "passaporte". Nesse espaço, ouve-se na rádio a locução de um jogo de futebol, mas as baterias descarregaram. Então, o protagonista volta para a casa e pega as pilhas do seu pai. Chegando em casa, ouve uma conversa sobre as dificuldades financeiras advindas da baixa colheita. William pergunta para o pai, Trywell, sobre a possibilidade do pagamento das mensalidades na escola, mas, somente conseguiria dar certeza após as chuvas pararem e depois da colheita.

Com as baterias nas mãos, ele volta para o estabelecimento e conserta o rádio. $\mathrm{Na}$ cena seguinte, no retorno para casa, Gilbert e William descobrem o envolvimento do professor Kachigunda com sua irmã, Annie. Gilbert sugere a ideia de destruir a bicicleta do docente, assim, não haveria possibilidade do casal se reencontrar. No entanto, William não consegue causar nenhum dano a bicicleta. Por conta disso, outra ideia foi apresentada por seu amigo: pegar o farol incorporado no guidão. Enquanto tenta desprender o farol, a personagem principal nota que existe um mecanismo que faz com que os pedais da bicicleta gerem eletricidade e forneçam energia para o farol. William não fez nada contra seu professor, entretanto, descobriu uma nova geração de energia.

O clima meteorológico modifica-se durante a narrativa. William novamente é advertido pelo Diretor da escola, Senhor Ofesi, sobre o pagamento das mensalidades. Devido à colheita ter sido ruim, Trywell recorre a Daniel Nguata, um amigo e funcionário da Venda de Tabaco AHL Chinkhoma e, assim, William o acompanha. A finalidade do pai do protagonista é viabilizar a retomada das terras vendidas - pelos membros da comunidade para estabilizar as inundações. Todavia, Nguata adverte para a impossibilidade. Salienta-se que durante o diálogo, o protagonista prestava atenção à conversa sobre as questões econômicas e políticas envolvendo os problemas da falta de apoio governamental.

Na fase Kukula (Growing/Crescer), por conta das inundações e, posteriormente, das colheitas ruins, Trywell sugere para que o Chefe Wiembe converse com o presidente - e candidato à reeleição - sobre as questões relacionadas aos grãos e a fome iminente da população. Enquanto isso, William volta para o aterro sanitário e encontra outra bateria e comenta com Gilbert sobre eletricidade e a imprevisão das chuvas.

Ao voltar para escola, de forma clandestina devido a advertência do diretor da escola sobre o pagamento das mensalidades, pergunta para o professor Kachigunda sobre a geração de energia a partir do farol na bicicleta. E, assim, aprende sobre o funcionamento do dínamo. Mas, para ter acesso a mais informações sobre eletricidade, solicita a ajuda do 
professor para conseguir entrar na biblioteca, pois não mais possuía cartão de acesso. Ambos guardam o segredo um do outro: William, sobre o envolvimento de Annie com Kachigunda, e o professor, sobre seu aluno frequentar a escola e a biblioteca sem efetuar o pagamento das mensalidades.

Assim, na cena que chamamos de $A$ descoberta do poder do vento, figura 2, o professor convence a bibliotecária de permitir que a personagem principal estude na biblioteca. Enquanto procurava livros sobre eletricidade, o jovem encontrou um chamado Using Energy, em que havia discussões sobre modelos de implantação de energia eólica nos Estados Unidos. A partir da leitura desse livro, nasce o projeto do moinho de vento, que será melhor desenvolvido adiante.

Figura 2: A descoberta do poder do vento

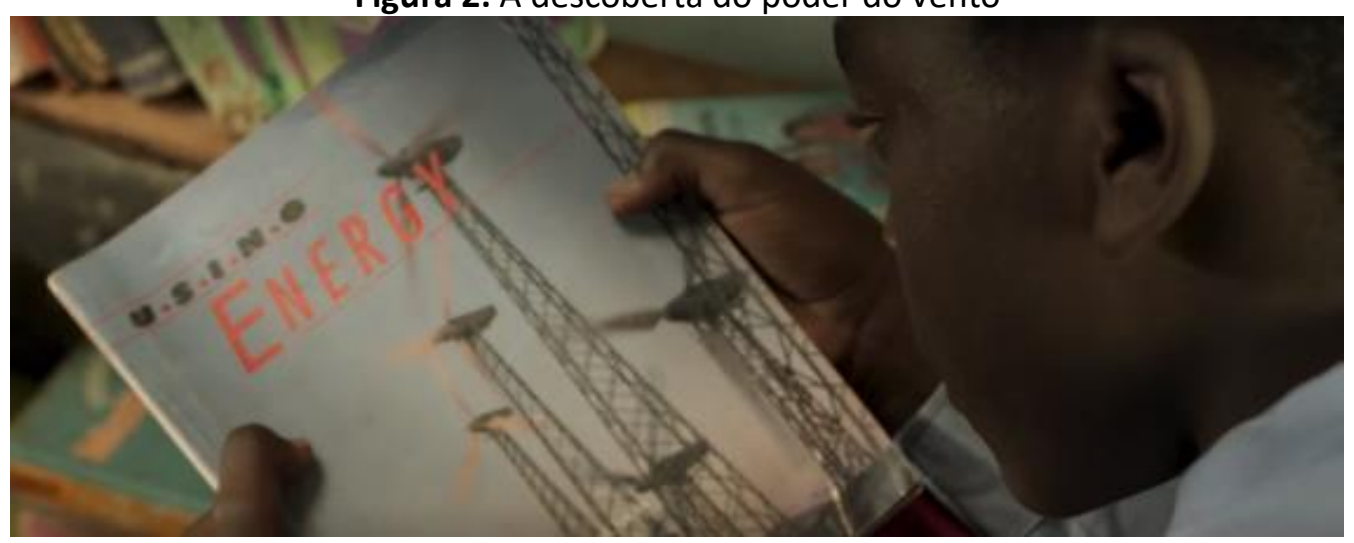

Fonte: O menino que descobriu o vento (2019)

Nas cenas seguintes, William volta ao aterro sanitário e, depois, participa de um comício/campanha eleitoral, junto com seus familiares, em que o presidente se apresentava para a população. Nessa ocasião, o Chefe Wiembe faz um pronunciamento sobre a fome, a miséria e o papel dos governantes em tempos de crise. Contudo, após isso, ele é brutalmente espancado por conta de seu posicionamento. Na cena seguinte, no período da noite, na casa do Chefe, pois, esse estava precisando de cuidados, Trywell solicita para que William o ajude na colheita, porque tem consciência de que o governo não ajudará os agricultores.

Na fase Kukolola (Harvest/Colher), as colheitas não foram boas. Com o descaso do governo, Trywell segue com outros membros da comunidade para uma manifestação que reivindica o posicionamento das autoridades frente à fome que se agravava. Enquanto isso, William explica para a bibliotecária a possibilidade de criar um moinho de vento e, assim, 
garantir água e colheita duas vezes ao ano. Ele dirige-se para a sala de aula, mas o Diretor Ofesi assumiu o lugar do professor Kachigunda. E, ao ver o jovem ocupando uma cadeira na sala de aula, ele o expulsa da escola. Ao retornar para casa, William observa o horizonte, a aridez e a seca da terra, como vemos na figura 3.

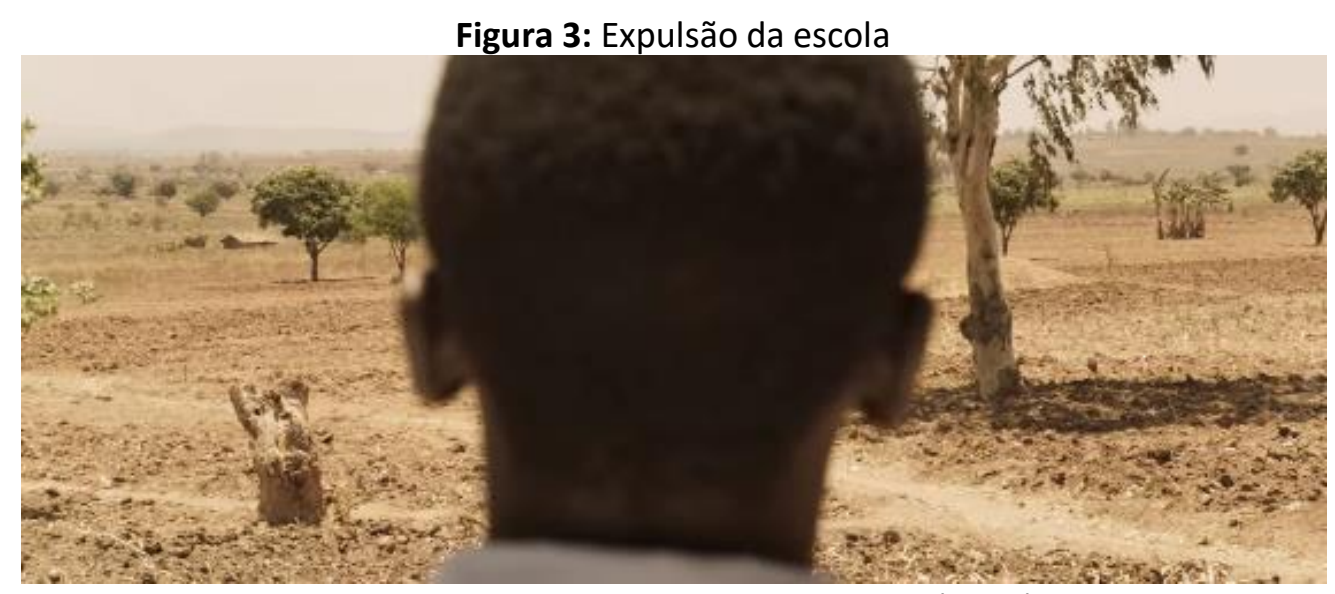

Fonte: O menino que descobriu o vento (2019)

Em seguida, sua mãe, Agnes, solicita para que ele compre grãos fornecidos pelo governo e, para isso, o garoto viaja alguns quilômetros com a bicicleta do pai. Pelo trajeto percebemos o desespero, os atos de violência e a falta de alimentos para as pessoas. São através dos olhos atentos do protagonista que conseguimos observar o caos e a dor. Em contrapartida, em outra cena, vemos Trywell, durante o percurso para uma cidade próxima, observando a movimentação das pessoas em sentido contrário ao carro em que estava. Dessa forma, ele percebe que o governo estava fornecendo alimentos e, então, decide voltar para casa.

William, com dificuldades, consegue comprar um saco de grãos, a pedido de sua mãe, e tenta voltar para casa. Por conseguinte, Agnes e Annie estão sozinhas, pois, tanto Trywell quanto o protagonista estão tentando voltar para casa. Em seguida, elas são saqueadas e perdem os grãos que haviam cultivado e que ajudariam a família durante a crise.

Em Njala (Hunger/Fome), a seca e a fome apresentam-se de formas muito mais intensas. William conversa com sua irmã sobre a importância do dínamo para seu projeto e construção do moinho de vento que viabilizaria o funcionamento da bomba d'água. Nas cenas seguintes, Annie, diante das complicações e da fome, abandona a família e foge com o professor, mas deixa para o seu irmão o dínamo. 
Trywell, Agnes e William, na procura por Annie e o professor, recorrem ao Diretor Ofesi para explicações. Durante a conversa, Agnes critica o posicionamento do diretor e o questiona sobre a união para atravessar momentos de crises. Assim, Ofesi pergunta para a família: "O que posso fazer Sra. Kamkwamba? Houve um silêncio, mas, em seguida, William responde: "Posso usar a biblioteca?" Dessa forma, a cena que intitulamos como 0 caminho da biblioteca, figura 4, corresponde as tentativas de a personagem principal colocar em prática a construção do moinho de vento. Para isso, ele se utiliza de vários livros da biblioteca, de peças encontradas no aterro sanitário e conta com a ajuda de seus amigos para fabricar um modelo de moinho.

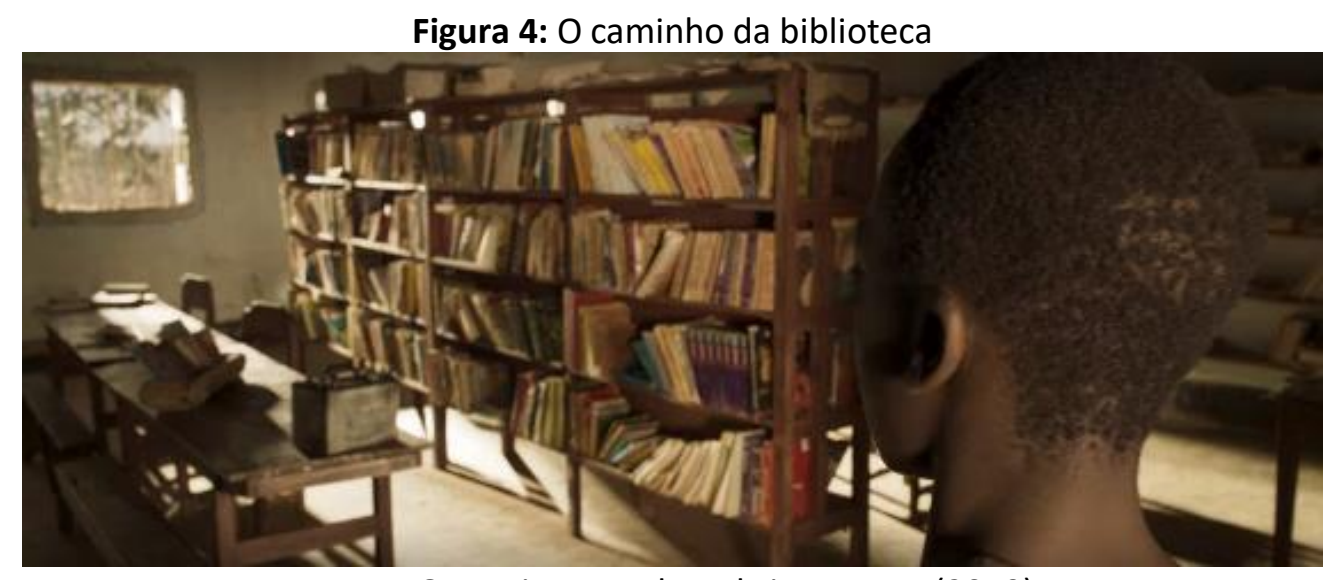

Fonte: O menino que descobriu o vento (2019)

William mostra ao seu pai o modelo elaborado e afirma que pode "fazer chover" e garantir a colheita nos próximos meses. Ao explicar os procedimentos para a construção de um moinho de vento, ou seja, a geração de energia a partir do vento, o jovem solicita a bicicleta do pai, visto que é uma peça fundamental para girar as lâminas maiores a partir das rodas. Questionado pelo pai sobre a devolução da bicicleta, o protagonista responde que não seria possível reutilizá-la.

Ao insistir, William comenta que é possível a aplicabilidade do projeto e que foi a escola a responsável por proporcionar o conhecimento para isso. Por conseguinte, Trywell irrita-se e pede para que ele cuide da terra, da agricultura e esqueça a escola. Ao perceber que seus amigos estão deixando a aldeia devido à fome e a seca, a personagem principal adverte-os sobre a possibilidade de criar um moinho capaz de gerar energia e assim fazer a bomba d'água funcionar. Então, seus amigos tentam ajudá-lo e buscam convencer Trywell, 
mas não tiveram êxito. Assim, diante de tantas perdas, Agnes, em prantos, convence seu esposo de ceder a bicicleta.

Enfim, chega a fase Mphepo (Wind/Vento). Vislumbramos a conciliação entre pai e filho e, durante a conversa, Trywell afirma ter fracassado. Mas o jovem protagonista afirma: "Não. Você não é um fracassado. Eu fui para escola". Assim, num gesto de gratidão, afeto e respeito, William assegurou ao pai: "posso fazer chover". Na cena $A$ esperança em meio à crise, figura 5, vemos a mobilização da comunidade para a construção do moinho e, por fim, a efetivação do projeto.

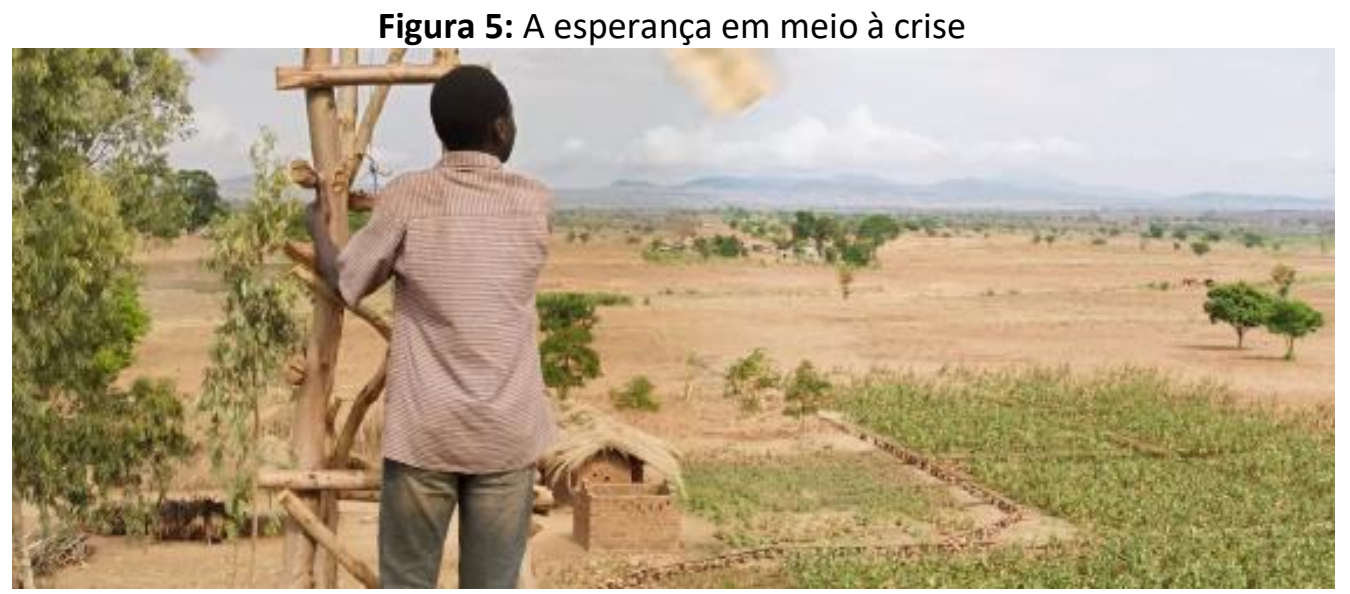

Fonte: O menino que descobriu o vento (2019)

William ganha bolsas de estudos para frequentar a escola e, posteriormente a Universidade. Conversando com seu pai, a personagem principal menciona que não irá abandonar a família e ajudará na agricultura. Entretanto, Trywell reflete sobre a construção do moinho e o fato de que, mesmo na distância, seu filho sempre estará presente, e por isso diz ao filho: "vai para escola".

Em linhas gerais, o filme apresenta a realidade de um país africano devastado por inundações e, posteriormente, pela seca, miséria e fome. Descrevemos algumas cenas, mas a narrativa mostra-nos a capacidade de William em ler seu mundo, ser crítico e empático para com os seus semelhantes. O protagonista percebeu na educação, na escola, na ciência e nos livros a oportunidade e, acima de tudo, a efetivação de modificar sua realidade.

Ao examinarmos os passos percorridos por William notamos que seu olhar é sensível e ao mesmo tempo crítico para com as questões sociais. As esferas que compõem a narrativa natureza, economia e ciência - estão interligadas com as visões de mundo da comunidade 
da qual William faz parte. Os estudos, mesmo em um curto tempo, potencializaram a criticidade da personagem e viabilizaram a transformação daquela comunidade.

b) As leituras dialógicas de William Kamkwamba: natureza, ciência e sociedade

Selecionamos e apresentamos anteriormente, em " $a$ ", cincos cenas, correspondentes a cada fase do filme, em que William nos insere em sua realidade em relação às esferas do Ciência/conhecimento, da Natureza e da Sociedade. Neste item "b", analisamos a relação entre o "menino", o ato de "descobrir" e o "vento", ou seja, as relações existentes entre sujeito e as esferas, haja vista que fazem parte das leituras dialógicas da personagem.

Numa visão bakhtiniana, não há sujeitos isolados e, portanto, suas interações são dialógicas no qual o "eu" e "outro" constituem-se mutuamente. Sendo assim, o contexto assume relevância, pois influencia na construção ideológica dos enunciados, ou seja, o papel do "outro" faz-se presente na constituição dos sentidos. Dessa maneira, o sujeito não é o único centro da enunciação, logo é um sujeito inacabado que se constitui a partir da relação entre eu, o outro e o contexto.

Nessa perspectiva, a análise das leituras empreendidas por William referente às esferas do Ciência/conhecimento, da Natureza e da Sociedade estão presentes nas cenas selecionadas. A personagem principal da narrativa conecta-se a tais esferas e, por conseguinte, ele as lê, as interpreta e as relaciona. Salientamos que ao utilizarmos o termo esferas temos como intuito demonstrar a capacidade da personagem em conectá-las, ou seja, William é leitor de seu mundo, visto que ele o interpreta e, através da criticidade e da transformação, busca modificá-lo.

Por conseguinte, a constituição do "outro" se faz por meio de elementos do contexto social e cultural dos sujeitos. Dessa forma, os diálogos do protagonista com o diretor da escola, com o professor de ciências, com o empresário da indústria de tabaco, com o chefe da aldeia, com a mãe e irmã, com amigos mais velhos e com os livros são aspectos relevantes para a constituição das leituras de mundo, como já apontado por Freire (1987).

De acordo com Sobral (2008, p. 22, grifos do autor), a partir das definições de Bakhtin, "só me torno eu entre outros eus. O sujeito, ainda que se defina a partir do outro, ao mesmo tempo o define, é o "outro" do outro: eis o não acabamento constitutivo do Ser, tão rico de ressonâncias filosóficas, discursivas e outras". A cada convivência, experiência e diálogo com outros saberes e sujeitos, William torna-se "outros eus". 
Na cena apresentada na figura 1, O desmatamento das árvores, temos a relação entre a personagem e os aspectos envolvendo as mudanças climáticas, as inundações, o descaso do governo e a falta de proteção para os agricultores em tempos de crise. Dessa forma, o contexto narrativo acerca da primeira cena selecionada abarca a jornada de William para a escola e seu contato com a disciplina Ciências ${ }^{4}$. Não podemos nos aventurarmos na ideia errônea de que conseguimos separar o sujeito de suas leituras de mundo, haja vista que sujeito e contexto relacionam-se em nível dialético, portanto, reduzir as experiências estimula visões estagnadas sobre o processo de aprendizagem e de letramentos.

A narrativa mostra-nos a sagacidade, curiosidade e vontade de William em ler, estudar, investigar e colocar em prática seus conhecimentos. Além disso, percebemos o orgulho dos pais em ingressá-lo na escola. Dessa forma, a esfera do Ciência/conhecimento é representada através dos livros, dos experimentos, das aulas e da descoberta da energia eólica. Essa esfera conecta-se com as problemáticas apresentadas pelo meio social em que o jovem está inserido como, por exemplo, a seca - esfera da Natureza - e a miséria e o descaso dos governantes - esfera da Sociedade.

Outro exemplo entre a relação dialética das esferas no filme é a investigação que William faz no aterro da Indústria de tabaco. Ao longo da narrativa, a personagem busca ferramentas, baterias, bomba d'água, lâminas e tubos com a finalidade de ajudá-lo nos estudos e, posteriormente, na efetivação do moinho. Assim sendo, nota-se a relação entre a esfera da Ciência/conhecimento e da Natureza:

Encontrei outra bateria, descarregada, mas se tirar todos as células ruins e conectar o positivo e o negativo com isso aqui, podemos fazer uma boa bateria. Mas, preciso de energia, precisa de eletricidade. Com eletricidade podemos concertar a bomba. Nós nunca sabemos como vai ser a chuva [grifo nosso] $^{5}$ (O MENINO..., 2019, 00:40:58 -00: 41:30).

Consequentemente, a preocupação advinda do excesso ou a falta de chuva está diretamente interligada com a esfera da Sociedade. Ressalta-se que a personagem, ao longo da narrativa, observa, ouve e participa das questões referente a sua comunidade. Isso

\footnotetext{
${ }^{4}$ Em conformidade com a narrativa, por "Ciências" compreende-se as disciplinas relacionadas ao campo das Ciências Exatas.

${ }^{5}$ Os diálogos inseridos na presente pesquisa referem-se a dublagem em português. 
contribuí para que William procure ajudar sua comunidade através do conhecimento adquirido na escola.

Entre as coletas de materiais e as aulas na escola, conseguimos observar um garoto atento aos acontecimentos em sua volta. De acordo com Coelho (1994, p. 119), "quem lê, em toda a dimensão do termo, conhece e pode construir relações ou alternativas que administrem as questões surgidas do embate palavra-mundo, sejam elas sociais, políticas ou culturais". Dessa forma, na cena apresentada na figura 2, a biblioteca é utilizada por William para ampliar seus saberes sobre o processo de geração de energia.

Ao vivenciar junto com sua família as dificuldades financeiras e a crise de alimentos em Malauí, William busca modificar a realidade. Para isso, recorre ao conhecimento, a biblioteca e aplicabilidade do seu projeto. Assim, para solucionar problemas advindos de fatores climáticos e sociais - esfera da Sociedade e da Natureza, - recorre ao conhecimento e, simultaneamente aos sujeitos mais próximos - bibliotecária, o professor e seus amigos no âmbito da esfera da Sociedade, nesse caso, membros da comunidade.

Após encontrar o livro Using Energy (figura 2), a bibliotecária pergunta: "encontrou o que estava procurando?". Dessa forma, o jovem constrói uma alternativa, a partir de sua descoberta, e percebe na natureza, em consonância com a ciência, a oportunidade de transformar sua comunidade. De acordo com Freire (1967, p. 55), "estudar é uma forma de reivindicar, de criar e de reescrever", ou seja, William reivindica uma realidade diferente e busca através das leituras enfrentar as dificuldades para colocar em prática seu projeto de energia eólica.

Ressalta-se que em Malauí a educação básica e a universitária não são públicas, ou seja, é necessária efetuar pagamento para ter acesso. Na obra em questão, vemos o grande interesse e a dificuldade da personagem em conseguir frequentar a escola por conta disso. Essas questões envolvendo a negação do acesso à educação as crianças e jovens em Malauí por falta de políticas públicas, investimento e posicionamento governamental são demonstrações da ideologia do capital para manter os sujeitos distantes da emancipação e, assim, um projeto que limita e reduz as possibilidades de futuros alternativos. De acordo com Freire (2000, p. 58), "reconhecendo os limites da educação, formal e informal, reconheço também a sua força, assim como porque constato a possibilidade que têm os seres humanos de assumir tarefas históricas". 
Dessa forma, o processo educacional para o jovem William foi limitado na medida em que existe uma ausência do Estado Democrático de Direito capaz de assegurar e garantir direitos fundamentais como, por exemplo, acesso ao ensino. Além disso, soma-se outros fatores econômicos e sociais, mas a personagem principal demonstrou força e coragem para interpretar sua realidade e transformá-la partir de leituras que ultrapassam os muros escolares.

O período de seca e a falta de chuvas agravaram a situação, apresentadas no contexto da cena na figura 4. O descaso dos governantes, a violência e saques advindo da escassez de comida, a morte de inúmeras pessoas e êxodo de membros da comunidade representam a intensificação da gravidade vivenciadas por homens, mulheres e crianças na narrativa. Entretanto, conforme as questões climáticas, sociais e econômicas se modificam, William compreende a urgência de ajudar seu pai e sua comunidade. Para isso, acreditou fielmente em seu projeto de construção do moinho de vento.

Em concordância com Martins (1988, p. 17),

[...] quando começamos a organizar os conhecimentos adquiridos, a partir das situações que a realidade impõe e da nossa atuação nela; quando começamos a estabelecer relações entre as experiências e a tentar resolver os problemas que se nos apresentam - aí então estamos procedendo leituras, as quais nos habilitam basicamente a ler tudo e qualquer coisa. [...] Dá-nos a impressão de o mundo estar ao nosso alcance; não só podemos compreendê-lo, conviver com ele, mas até modificá-lo à medida que incorporamos experiências de leitura.

O sujeito emerge na relação com o outro, ou seja, um sujeito dialógico, em que a palavra do outro transforma-se em constante caráter criativo (FREITAS, 2005, p. 295). Nas cenas apresentadas nas figuras 4 e 5, observamos William em permanente diálogo com amigos, com a bibliotecária, com o professor de ciências e com sua irmã sobre a possibilidade de "fazer chover". Dessa forma, o jovem aprende e ensina num processo pela busca do conhecimento e a solução de problemas sociais.

A capacidade da personagem principal de estar em constante transformação e em contato com outros sujeitos, com o meio social e com a natureza corroboram o entrecruzar e interpenetrar em outras experiências. O protagonista apresenta-se como agente transformador em constante dinamismo com sua realidade. Portanto, o "outro" não está fora de mim, mas como alguém que me constitui e, assim, a minha existência dar-se-á pelo processo de constituição de um "eu" e do olhar do "outro". São construções mútuas. 
$\mathrm{Na}$ cena em que William mostra a seu pai o projeto do moinho de vento encontramos, sua vontade e persistência de continuar a transformar a realidade. Para a construção, em tamanho real, foi necessária a utilização da bicicleta de Trywell. Porém, ao descobrir que não poderia reutilizá-la, seu pai o questiona:

Trywell: William, você está vendo o que está acontecendo?

William: Sim, Senhor!

Trywell: Pessoas estão morrendo, entende isso?

William: Isso vai ajudar todo mundo.

Trywell: Tire essa ideia estúpida de perto de mim [...]. Por que ainda está falando?

William: Porque tem muitas coisas que sei que o Senhor não sabe.

Trywell: Por que você sabe construir brinquedos?

William: Por causa da escola. (O MENINO..., 2019, 1:23:04-1:24:02)

O jovem tem plena consciência da realidade e a materialidade disso advém na prática da luta para construir um moinho de vento para geração de energia. Na cena $A$ esperança em meio à crise, figura 5, Agnes convence Trywell de ajudar o filho. Por conseguinte, a conversa entre pai e filho, sobre a efetivação do projeto do moinho, reflete nas questões sobre o diálogo em sua relação horizontal, fundado no amor e na humildade, em que "a confiança de um pólo no outro é consequência óbvia" (FREIRE, 1987, p. 46). E isso é retomado nas últimas cenas do filme sob o olhar do pai para com a atitude de compaixão, esperança e afeto do filho.

Em um cenário de miséria, violência e fome, a palavra torna-se primordial, pois a partir dela William busca convencer sua irmã, seu pai e seu amigos próximos de que é capaz de transformar aquela dura realidade através do conhecimento científico. Considerando as vivências da personagem, afirmamos que:

a leitura vai, portanto, além do texto (seja ele qual for) e começa antes do contato com ele. O leitor assume um papel atuante, deixa de ser mero decodificador ou receptor passivo. E o contexto geral em que ele atua, as pessoas com quem convive passam a ter influência apreciável em seu desempenho de leitura. Isso porque o dar sentido a um texto implica sempre levar em conta a situação desse texto e de seu leitor. (MARTINS, 1988, p. 32-33).

O protagonista dialoga com as esferas do Ciência/conhecimento, Natureza e Sociedade e os relaciona na medida em que se indaga sobre os acontecimentos que afligem 
sua aldeia e sua comunidade. Antes de ler livros, "o menino que descobriu o vento", com sensibilidade, leu seu mundo. A realidade social que vivemos nos forma enquanto sujeitos históricos. Ao chegarmos na escola, entramos com uma bagagem social. Portanto, William descobria-se a partir de outros olhares, de outros espaços, de outras conversas e de outras memórias, pois

[...] podemos ir mais longe e dizer que a leitura da palavra não é apenas precedida pela leitura do mundo, mas por uma certa forma de "escrevê-lo" ou de 'reescrevê-lo', quer dizer, de transformá-lo através de nossa prática consciente. (FREIRE, 1989, p. 13).

O leitor pré-existe à descoberta do significado das palavras escritas. De acordo com Martins (1988, p. 17), as "experiências de vida, desde as mais elementares e individuais às oriundas do intercâmbio de seu mundo pessoal e o universo social e cultural circundante" contribuem para formação social e cultural dos sujeitos. A escola tornou-se espaço para abrir caminhos e solucionar problemas. Com a escassez de alimentos, com a seca e fome, os pais do jovem não conseguiram garantir a escola por falta de pagamento, mas isso não o impediu de continuar.

William transformou sua comunidade e assim moveu outras pessoas e tornou-se um inquieto, um descobridor e apaixonado pela ciência. Recorremos a Paulo Freire sobre o processo de inquietação, que vê

[...] a curiosidade como inquietação indagadora, como inclinação ao desvelamento de algo, como pergunta verbalizada ou não, como procura de esclarecimento, como sinal de atenção que sugere alerta faz parte integrante do fenômeno vital. Não haveria criatividade sem a curiosidade que nos move e que nos põe pacientemente impacientes diante do mundo que não fizemos, acrescentando a ele algo que fazemos. (FREIRE, 1996, p. 15)

A leitura do mundo e a leitura da palavra caminham juntas (FREIRE, 2009), pois uma completa a outra. Assim, as relações sociais com o "outro", com as experiências e circunstâncias proporcionam a formação do leitor-cidadão. A leitura é ampliada a cada contato com o contexto social em que o sujeito-leitor está inserido. A formação crítica do leitor ocorre em vários aspectos em níveis lexicais, gramaticais, bem como por meio do conhecimento de mundo (KLEIMAN, 2004). 
Dessa forma, o conhecimento de mundo e a compreensão da linguagem devem estar conectados com o contexto social do sujeito-leitor. O leitor é um sujeito do/no mundo construindo e produzindo sentidos. Na concepção freireana, ao estarmos em contato com o mundo, ampliamos nossos olhares. A constituição do sujeito-leitor estará relacionada com os aspectos sociais, econômicos, políticos e culturais. Consideramos William Kamkwamba como um sujeito-leitor de seu mundo que através da leitura do seu contexto social, da natureza e da economia buscou enfrentar os problemas. Enfim, aprender a ler significa aprender a ler o mundo e, portanto, dar sentido a ele e a nós próprios.

Para os leitores que assistiram ou não ao filme, consideramos que as palavras de Mia Couto, escritor e poeta moçambicano, fornecem a síntese da trajetória de William:

[...] a ideia de leitura aplica-se a um vasto universo. Nós lemos emoções nos rostos, lemos os sinais climáticos nas nuvens, lemos o chão, lemos o Mundo, lemos a Vida. Tudo pode ser página. Depende apenas da intenção de descoberta do nosso olhar. Queixamo-nos de que as pessoas não lêem livros. Mas o deficit de leitura é muito mais geral. Não sabemos ler o mundo, não lemos os outros (COUTO, 2011, p. 103).

Após a construção do moinho, William conseguiu bolsas de estudos para continuar estudando, tanto na escola quanto em uma universidade. No último diálogo, no filme, Trywell menciona que mesmo na distância seria impossível esquecer de William, pois ele sempre estaria presente na aldeia. E, por último, disse ao filho: "Vai para escola". Essa frase é importante para compreendermos que a educação para família Kamkwamba sempre foi uma prioridade. Mas, com as dificuldades financeiras, a escassez de grãos e seca, não possibilitaram fornecer ao filho o acesso à escola.

No topo de seu projeto, figura 5, construído pelos membros de sua aldeia a partir das inúmeras leituras que o jovem fez e, acima de tudo, das leituras de rostos, de terra, do céu e dos corações de seus antepassados, observamos as inúmeras janelas que William nos abriu; as frações que aprendemos uns com outros. Por isso, escolhemos tais cenas, pois são janelas e por meio delas somos convidados a ver outros mundos, outros espaços e outras experiências. Mais do que paisagens, olhamos as leituras de um mundo do "outro". O "outro" que somos "nós". Em suma, a leitura nos transforma e somos transformados por ela. 


\section{CONSIDERAÇÕES FINAIS}

No presente artigo apresentamos alguns apontamentos sobre o poder da leitura na sociedade. Ler a realidade, ler as relações humanas - com a natureza -, ler o presente e o passado. As múltiplas leituras são partes integrantes e importantes para as análises da sociedade. Dessa forma, de acordo a posição de Paulo Freire, para transformar a Educação brasileira e consigo os sujeitos que nela estão, é necessário coragem de posicionamento, revisitação dos saberes e as mudanças sociais a partir do diálogo entre sujeito e sociedade.

A leitura de mundo fornece compreensão ao conteúdo do texto e, assim, evoca o sujeito como construtor de sua história (FREIRE, 1989). Nas articulações entre as leituras é que o professor desenvolve nos alunos a capacidade de criticidade. Portanto, o posicionamento dialético presente na obra freiriana permite-nos compreender a trajetória de William no longa-metragem, pois o mundo não se encontra num processo linear, mas sim em um processo de relações de fatores internos e externos, do individual/coletivo e estruturas.

A experiência educacional e as contribuições de Paulo Freire continuam pertinentes para os dias atuais. Em função dos diálogos estabelecidos pelo educador para efetivar uma educação cuja finalidade seja promover um ensino libertário, também encontramos elementos enriquecedores para refletirmos sobre sujeitos e suas ações no mundo. Ele contribuiu para as concepções de escola, de leitura de mundo e ações voltadas para os aspectos políticos, sociais e econômicos.

Em concordância com o pensamento freireano (1996), gostamos de ser gente, porque somos feitos da relação histórica com outras pessoas. Lemos, acima de tudo, sujeitos cujas trajetórias percorrem a luta pela sobrevivência e por Justiça Social. Portanto, problematizamos o presente em busca de futuros mais justos e iguais. Lutamos para que jovens como William possam crescer e mudar a realidade sem seres impedidos por questões políticas ou econômicas. Com Freire, aprendemos a olhar janelas e aprender com garotos sonhadores como William Kwakwamba e sua família. 


\section{REFERÊNCIAS}

BAKHTIN, Mikhail. Estética da Criação Verbal. 4. ed. São Paulo: Martins Fontes, 2003.

BAKHTIN, Mikhail. Marxismo e Filosofia da Linguagem: problemas fundamentais do método sociológico da linguagem.13. ed. São Paulo: Hucitec, 2009.

COELHO, Lígia Martha C. C. Estudo Dirigido: da compensação à emancipação. Tese de doutorado. Rio de Janeiro, UFRJ: 1994.

COUTO, Mia. E se Obama fosse africano? Ensaios. São Paulo: Companhia das Letras, 2011.

CRUZ, Ricardo Gauterio; BIGLIARDI, Rossane Vinhas; MINASI, Luis Fernando. A dialética materialista de Paulo Freire como método de pesquisa em educação. Conjectura: Filos. Educ., Caxias do Sul, v. 19, n. 2, p. 40-54, maio/ago. 2014.

FREIRE, Paulo. Educação como prática de liberdade. Rio de Janeiro: Paz e Terra, 1967.

FREIRE, Paulo. Pedagogia do oprimido. Rio de Janeiro: Paz e Terra, 1987.

FREIRE, Paulo. Pedagogia da autonomia: saberes necessários à prática educativa. São Paulo: Paz e Terra, 1996.

FREIRE, Paulo. Pedagogia da indignação: cartas pedagógicas e outros escritos. São Paulo, SP: Ed. da Unesp, 2000.

FREIRE, Paulo. A importância do ato de ler: em três artigos que se completam. São Paulo: Autores Associados: Cortez, 2009 [1989].

KLEIMAN, Angela B. Abordagens da leitura. SCRIPTA, Belo Horizonte, v. 7, n. 14, p. 13-22, 10 sem. 2004.

LIMA, Paulo Gomes. Uma leitura sobre Paulo Freire em três eixos articulados: o homem, a educação e uma janela para o mundo. Pro-Posições, v. 25, n. 3 (75), p. 63-81, 2014.

MARTINS, Maria Helena. O que é leitura? 9. ed. São Paulo: Brasiliense, 1988.

MENEZES, Paulo Roberto Arruda de. Cinema: imagem e interpretação. Tempo Social, Rev. Sociol. USP, S. Paulo, 8(2): 83-104, outubro de 1996.

O MENINO que descobriu o vento. Direção: Chiwetel Ejiofor. Produção da Plataforma Streaming Netflix. Reino Unido: Netflix, 2019. Online.

ROJO, Roxane. Letramento e capacidades de leitura para a cidadania. São Paulo: SEE CENP, 2004. Texto apresentado em Congresso realizado em maio de 2004.

ROJO, Roxane. Letramentos múltiplos, escola e inclusão social. São Paulo: Parábola, 2009. 
SOARES, Magda. Letramento: um tema em três gêneros. 3 ed. Belo Horizonte: Autêntica Editora, 2014.

SOBRAL, Adail. Ato/Atividade e evento. In: BRAIT, Breth (org.). Bakhtin: conceitos-chave. 4. ed. São Paulo: Contexto, 2008, p. 11-36.

Recebido em 20 de dezembro de 2020.

Aprovado em 06 de abril de 2021.

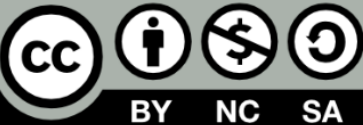

